\title{
Greenhouse gas emissions and Irish agriculture in 2020
}

T Donnellan, K Hanrahan

Teagasc, Galway, Ireland

Email: trevor.donnellan@teagasc.ie

Background With agriculture contributing over one quarter of Ireland's total greenhouse gas (GHG) emissions, the Irish agricultural sector is relatively unique in the EU. The EU has set Member State targets for reducing GHG emissions. For Ireland, at a minimum, the target is a reduction of $20 \%$ by 2020 in overall GHG emissions from all sectors of the economy, relative to the 2005 level. The reduction target would increase to $30 \%$ if a successor agreement to the Kyoto protocol is achieved. It remains unclear to what extent the agricultural sector might be required to contribute to the achievement of Ireland's GHG emission reduction target. However, in the context of reducing agriculture's GHG emissions, those agricultural activities that contribute to GHG emissions and that are currently marginally economic or uneconomic (in the sense of their profitability) will almost certainly be the first focus of policy makers in their search for the least cost abatement policy.

While science and technology holds out the promise of a more carbon efficient agricultural sector, it should be understood that there are limits to what can be achieved within the short timeframe to 2020. The contribution to GHG abatement of the technologies that flow from agricultural production research programmes will first have to be accepted by the IPCC. Farmers will then have to adopt the technologies proposed. Experience suggests that neither of these processes is rapid or guaranteed.

A $30 \%$ GHG reduction target implies a level of emissions from Irish agriculture in 2020 of $13.29 \mathrm{Mt} \mathrm{CO}_{2}$ Eq. (exclusive of emissions by agriculture from fuel combustion). Such a reduction in emissions could not occur overnight and would need to take place gradually in the period to 2020. In this paper we examine the likely future level of GHG emissions from Irish agriculture in the absence of technical abatement strategies.

Methods Future GHG emission levels from agriculture will be the product of emission factors and future levels of agricultural activity. Considerable work has been done to provide GHG emission factors which are specific to Ireland, notably the work by O'Mara et al. (2006). The other element of the future GHG emissions equation, are the future levels of agricultural activity. We need to use economics to establish the likely future level of activity.

In Ireland this economic contribution is provided by the FAPRI GHG model. It is a sister component of the FAPRI-Ireland agricultural sector model and the FAPRI EU-GOLD agricultural sector model described in Hanrahan (2001). The agricultural sector models allow projections of future levels of agricultural activity and the FAPRI GHG model then uses a mix of national and default emission factors to convert this activity to annual estimates of GHG emissions out to 2020 .

While the primary concern of this research programme is to understand how new agricultural policies or new trade policies will impact on the level of future agricultural GHG emissions, this work also provides the set of agricultural GHG emission projections for Ireland which is used by Irish Government Departments and reported by Ireland's Environmental Protection Agency in fulfilment of Kyoto Protocol requirements.

Results Under the Reference scenario, GHG emissions from Irish agriculture decrease by $11 \%$ from $18.9 \mathrm{Mt} \mathrm{CO}_{2} \mathrm{Eq}$. in 2005 to $16.6 \mathrm{Mt} \mathrm{CO}_{2}$ Eq. in 2020. Under the Reference scenario there is a decrease in drystock animal numbers, however, in the absence of milk quotas, the impact on GHG emissions of this reduction in activity is largely offset by increasing emissions per cow and an increase in the number of dairy cows and their progeny. Under the Reference scenario the total cattle population in Ireland declines by $10 \%$ between 2005 and 2020 . The production of beef in Ireland also declines, with production in 2020 under the Reference scenario 14\% lower than in 2005.

Conclusion Agricultural policy and market returns will lead to a reduction in GHG emissions from agriculture over this decade. However, even with such reductions, the level of emissions from agriculture in 2020 is likely to be well short of a $30 \%$ GHG emission deduction target. A further 3.5 million tonnes $\mathrm{CO} 2$ eq. emission reduction would be required to meet the target by 2020. This would leave policy makers with a number of tough choices. Impose larger cuts in other nonemissions trading sectors or impose policies which restrict the size of the agriculture sector so that emissions are further reduced. The implementation of technical abatement measures in agriculture would limit the extent to which agricultural production would need to be reduced to meet possible agricultural emission reduction targets.

\section{References}

O’Mara, F., M.Ryan, J. Connolly, P. O’Toole, O. Carton, J.J. Lenehan, D. Lovett, B. Hyde, E. Jordan and M. Hawkins 2006. Climate change - Estimation of Emissions of Greenhouse Gases from Agriculture and Strategies for their Reduction, EPA

Hanrahan, K. 2001. The EU GOLD Model 2.1: An Introductory Manual. Mimeo, Teagasc, Dublin. 